\title{
Abdominal obesity in adolescents: Development of age-specific waist circumference cut-offs linked to adult IDF criteria
}

\author{
Jorge Bravo ${ }^{1}$ | Armando M. Raimundo ${ }^{1}$ | Diana A. Santos ${ }^{2}$ | \\ Rafael Timón $^{3}$ ～Luís B. Sardinha ${ }^{2}$
}

${ }^{1}$ Department of Sport and Health, Research Center in Sports, Health Sciences and Human Development, Science and Technology School, University of Évora, Évora, Portugal

${ }^{2}$ Exercise and Health Laboratory, CIPER, Faculdade de Motricidade Humana, Universidade de Lisboa, Portugal

${ }^{3}$ Department of Didactics of Music, Plastic and Corporal Expression, Sports Science School, University of

Extremadura, Cáceres, Spain

\section{Correspondence}

Luís B. Sardinha, Exercise and Health

Laboratory, CIPER, Faculdade de

Motricidade Humana, Universidade de

Lisboa, Estrada da Costa, 1499-002,

Cruz-Quebrada, Portugal.

Email: 1sardinha@fmh.ulisboa.pt

\section{Funding information}

Grant sponsor: DAS is supported by a scholarship from the Portuguese Foundation for Science and Technology; grant number: SFRH/BPD/92462/2013.

\begin{abstract}
Objectives: The purpose of this study was to develop age- and sex-specific waist circumference (WC) cut-off points, linked to older adolescent and adult criteria for abdominal obesity, to be applied to children in the clinical setting.

Methods: A total of 16,788 adolescents aged 10 to 16 years were assessed for WC. Smoothed age and sex-specific WC curves were obtained using Cole's LMS method.

Results: Percentiles that corresponded to the International Diabetes Federation (IDF) recommendations used for older adolescents and adults $(16+$ years old) were the $97^{\text {th }}$ percentile for boys and the $87^{\text {th }}$ percentile for girls. Using these cutoffs, a total of 368 boys and 1138 girls were categorized as abdominally obese, in contrast to 1654 boys and 987 girls that were identified using the current IDF pediatric criteria $\left(90^{\text {th }}\right.$ percentile).

Conclusions: We provide age- and sex-specific cut-off points that can be used to identify abdominal obesity in adolescents. The present findings provide a tool that can be used in the clinical setting for the early detection and prevention of adult obesity. Population-specific cutoffs may be required for pediatric ages to diagnose children at risk.
\end{abstract}

\section{1 | INTRODUCTION}

The prevalence of pediatric overweight and obesity has increased substantially over the past decades in both developed and developing countries ( $\mathrm{Ng}$ et al., 2014; de Onis, Blosser, \& Borghi, 2010). The risk of overweight and obese youth becoming overweight adults is at least twice as high as their regular-weight peers (Singh, Mulder, Twisk, Van Mechelen, \& Chinapaw, 2008).

Body mass index (BMI) is a widely recognized surrogate of obesity that is routinely used to identify overweight and obese individuals in pediatric populations (Cole, Bellizzi, Flegal, \& Dietz, 2000; de Onis et al., 2007). However, BMI does not provide information on body fat distribution
(Brambilla et al., 2006) and thus waist circumference (WC) has been acknowledged as a better predictor of metabolic risk (Kahn, Imperatore, \& Cheng, 2005; Lee, Bacha, Gungor, \& Arslanian, 2006b; Savva et al., 2000).

WC is a practical anthropometric measure of abdominal obesity, in terms of both central subcutaneous and visceral fat, and in pediatric populations it is an independent predictor of insulin resistance, lipid levels, and blood pressure (Freedman et al., 2007; Hirschler, Aranda, Calcagno, Maccalini, \& Jadzinsky, 2005; Lee, Bacha, \& Arslanian, 2006a; Lee et al., 2006b; Mesa et al., 2006; Moreno et al., 2002; Rosini et al., 2013; Savva et al., 2000), all components of the metabolic syndrome (MetS).

The International Diabetes Federation (IDF) states that abdominal obesity is the most important criteria of the MetS 
(Alberti, Zimmet, \& Shaw, 2006; Zimmet et al., 2007). The IDF suggests that a WC above $94 \mathrm{~cm}$ in men and $80 \mathrm{~cm}$ in women (Alberti et al., 2006) should be used for European descendent adults and older adolescents $(16+$ years old) as the criteria for abdominal obesity. The early diagnosis of MetS in adolescents would help to identify those at increased risk (Eisenmann, Welk, Wickel, \& Blair, 2004; Katzmarzyk et al., 2001). The IDF consensus (Zimmet et al., 2007) established that below 10 years of age the MetS cannot be diagnosed, while from 16 years old and older the criteria is the same as that used for adults. Consequently, the IDF developed a new definition for the diagnosis of MetS in adolescents aged $10-<16$ years using modified adult criteria with all risk factor cut-off points being similar to those for adults with the exception of $\mathrm{WC}$, for which the $90^{\text {th }}$ percentile was established as a criteria for abdominal obesity. Accordingly, youth with a WC above the $90^{\text {th }}$ percentile are more likely to present multiple risk factors than their counterparts (Zimmet et al., 2007). On the other hand, hormonal, metabolic and psychological changes in adolescence increase the level of instability in the control of cardiovascular risk factors, due to the direct influence of insulin sensitivity (Tfayli \& Arslanian, 2007), suggesting that the $90^{\text {th }}$ percentile might not compensate for adolescents' age- and sex-specific metabolic variations. Therefore, the IDF states in its consensus report that an effort should be made to reassess these WC cut-off points to modify its guidelines, if necessary, based on the new data (Zimmet et al., 2007).

To relate the IDF cut-off point for WC that is used in those aged 16 years and older (Alberti et al., 2006) to the need for adjustment due to adolescence, the aim of this study was to develop age- and sex-specific WC cut-off points linked to adult criteria for 10 to $<16$-year-old boys and girls using the Lambda Mu Sigma (LMS) growth curve, a method previously described (Benmohammed, Valensi, Balkau, \& Lezzar, 2016; Jolliffe \& Janssen, 2007).

\section{2 | METHODS}

\section{1 | Participants}

Data derived from a nationally representative cross-sectional school-based survey, designed to evaluate physical activity, physical fitness, incidence of overweight/obesity, and related factors in the Portuguese population. Study design and sampling were described in another study (Sardinha et al., 2011). Data were collected by means of proportionate stratified random sampling by location (the Portuguese administrative regions of Alentejo, Algarve, Centro, Lisboa, and Norte) and the number of students by age and sex in each location.

The sample included 16,788 adolescents aged 10 to 16 years, and written informed consent was obtained from their parents or guardians (89\% response rate). Participants with a WC above \pm 5 SD from the corresponding age- and sex- $Z$ score were excluded from the analysis, resulting in a final sample total of 8277 boys and 8511 girls. The protocol and procedures for this study were approved by the local Ethics Committee and conducted in accordance with the Declaration of Helsinki for human studies of the World Medical Association (World Medical Association, 2013).

\section{2 | Anthropometric measurements}

WC was measured using anthropometric tape in accordance with the National Health and Nutrition Examination Survey (NHANES) procedures (CDC, 2007). With the participant in a standing position, a flexible tape was placed horizontally just above the uppermost lateral border of the right ilium crest at the end of a normal expiration (CDC, 2007). WC was recorded to the nearest $0.1 \mathrm{~cm}$ and the mean of two measurements was obtained. If the two measurements differed by more than $1 \mathrm{~cm}$, a third measurement was taken, and the two closest measurements were averaged. A correction formula suggested by Patry-Parisien and colleagues (Patry-Parisien, Shields, \& Bryan, 2012) was then applied to report measurements according to WHO procedures (midway between the lower rib margin and the iliac crest), given that the IDF MetS definition (Alberti et al., 2006) is in accordance with WHO procedures. The formula applied is described in Equations 1 and 2:

$$
\begin{aligned}
\text { Boys : Predicted } \mathrm{WC}_{\mathrm{WHO}}(\mathrm{cm})=\left[\mathrm{WC}_{\mathrm{NHANES}}(\mathrm{cm})\right. \\
\quad+0.89911-0.05164 \times \text { age }(\text { years })] / 1.01829 \\
\text { Girls : Predicted } \mathrm{WC}_{\mathrm{WHO}}(\mathrm{cm})=\left[\mathrm{WC}_{\text {NNHANES }}(\mathrm{cm})\right. \\
\quad+0.70299-0.12297 \times \text { age }(\text { years })] / 1.01891
\end{aligned}
$$

Body height and body weight were determined by standard anthropometric methods. Height was measured to the nearest $\mathrm{mm}$ in bare or stocking feet with the adolescents standing upright against a Holtain portable stadiometer. Weight was measured to the nearest $0.10 \mathrm{~kg}$, lightly dressed (underwear and t-shirt) using a portable digital beam scale (Tanita Inner Scan BC 532).

Body mass index was calculated from the ratio of weight/ height $^{2}\left(\mathrm{~kg} / \mathrm{m}^{2}\right)$. Subjects were classified into non-overweight, overweight and obese categories according to age- and sexspecific cut-off points proposed by the International Obesity Task Force (IOTF) (Cole et al., 2000) and by the World Health Organization (WHO) (de Onis et al., 2007).

\section{3 | Statistics}

Age was calculated as the difference between the date of birth and date of data collection. Each age group was categorized according to the midpoint of an age range. For 
example, the group of participants aged 16 years included all participants between 15.50 and 16.49 years.

Age- and sex-specific growth curves were estimated using Cole's LMS method (Cole \& Green, 1992). The summary distribution of the WC is represented by Lambda (L), $\mathrm{Mu}(\mathrm{M})$, and Sigma (S) curves, representing the skewness, median, and coefficient of variance of the distribution at each age, respectively.

The WC growth curve was linked to the respective IDF cutoff point established for older adolescents $(+16$ years old) (Alberti et al., 2006). The first step in creating a growth curve involved defining the Z-score (or percentile) that corresponded to the IDF cut-off point at the age of 16 years (94 $\mathrm{cm}$ for boys and $80 \mathrm{~cm}$ for girls), represented by the following equation:

$$
\mathrm{Z} \text { score }=\left[(\mathrm{Y} / \mathrm{M})^{\mathrm{L}}-1\right] /(\mathrm{LS})
$$

where $\mathrm{Y}$ is the adult cut-off point and $\mathrm{L}, \mathrm{M}$, and $\mathrm{S}$ are the respective values at the age of 16 (Cole \& Green, 1992). The second step involved calculating points on the growth curve at each age by regressing the previously defined $\mathrm{z}$-score through adolescence and childhood, as follows:

$$
\text { point on curve }=\mathrm{M}(1+\mathrm{LSz})^{1 / \mathrm{L}}
$$

where $\mathrm{L}, \mathrm{M}$, and $\mathrm{S}$ are the respective age- and sex-specific values and $\mathrm{z}$ is the $\mathrm{z}$-score that corresponded to the adult cutoff point (Cole \& Green, 1992). Accordingly, by defining the percentile that corresponded to the IDF cut-off point at 16 years of age and regressing through adolescence to the end of childhood, at the age of 10 years, adolescent cut-off points for WC were able to be linked to those of adults.

The IDF recommended percentile for adolescents was estimated using Cole's LMS method (Cole \& Green, 1992).

Data management, descriptive, and analysis were performed using IBM SPSS ${ }^{\circ}$ Statistics version 22 for Windows (SPSS Inc., an IBM Company, Chicago IL, USA), whereas LMS regressions were performed using LMS Pro software (The Institute of Child Health, London, UK).

\section{3 | RESULTS}

In Table 1 are presented the descriptive characteristics of participants by age and sex. Using IOTF cut-off points the prevalence of overweight and obesity was $18.2 \%$ and $6.0 \%$ in boys, and $18.0 \%$ and $5.0 \%$ in girls, respectively, whereas the prevalence of overweight and obesity was $22.0 \%$ and $11.5 \%$ in boys, and $20.7 \%$ and $7.7 \%$ in girls, respectively, when using WHO cut-off points.

Table 2 lists the cut-off point for each age group in accordance with the criteria used: current pediatric IDF criteria $\left(90^{\text {th }}\right.$ percentile) and age-specific growth curves linked to
TABLE 1 Sample waist circumference means and SD in boys and girls

\begin{tabular}{|llll} 
& $\begin{array}{l}\text { All Sample } \\
(\boldsymbol{n}=\mathbf{1 6 , 7 8 8})\end{array}$ & $\begin{array}{l}\text { Boys } \\
(\boldsymbol{n}=\mathbf{8 2 7 7})\end{array}$ & $\begin{array}{l}\text { Girls } \\
(\boldsymbol{n}=\mathbf{8 5 1 1})\end{array}$ \\
& Mean $( \pm \mathrm{SD})$ & Mean $( \pm \mathrm{SD})$ & Mean $( \pm \mathrm{SD})$ \\
\hline WC $(\mathrm{cm})$ & $69.7( \pm 8.8)$ & $71.0( \pm 9.0)$ & $68.5( \pm 8.4)$ \\
\hline BMI (\%) IOTF & & & \\
\hline $\begin{array}{l}\text { Non overweight } \\
\text { Overweight }\end{array}$ & 76.3 & 75.7 & 76.9 \\
Obese & 18.1 & 18.2 & 18.0 \\
& 5.5 & 6.0 & 5.0 \\
BMI (\%) WHO & & & \\
\hline $\begin{array}{l}\text { Non overweight } \\
\text { Overweight }\end{array}$ & 69.0 & 66.4 & 71.5 \\
Obese & 21.3 & 22.0 & 20.7 \\
\end{tabular}

BMI, Body mass index; SD, Standard deviation; WC, Waist circumference.

the cutoff points at 16 years of age, indicating the number of adolescents identified as being abdominally obese according to both standards. Additionally, Figure 1 shows the growth curves for both criteria in boys and girls.

Based on the LMS growth curves method, the percentiles that corresponded to IDF recommendations for adults were the $97^{\text {th }}$ and the $87^{\text {th }}$ percentiles for boys and girls, respectively (Figure 1).

Overall, when using the $90^{\text {th }}$ percentile as suggested by the IDF, 1654 boys were identified as abdominally obese. When using the LMS growth curve method linked to the recommended adult cut-off point, only 368 were within this category. Considering girls, a total of 987 participants were identified as abdominally obese using current IDF pediatric criteria, but, when using the LMS growth curves method linked to the recommended adult cut-off point, this number increased to 1138 .

\section{4 | DISCUSSION}

WC percentiles have been produced for pediatric ages in different populations worldwide (Eisenmann, 2005; Fernandez, Redden, Pietrobelli, \& Allison, 2004; Fredriks, van Buuren, Fekkes, Verloove-Vanhorick, \& Wit, 2005; Hatipoglu et al., 2008; Inokuchi, Matsuo, Anzo, Takayama, \& Hasegawa, 2007; McCarthy, Jarrett, \& Crawley, 2001; Moreno et al., 1999; Sardinha et al., 2011, 2012; Schwandt, Kelishadi, \& Haas, 2008; Yan et al., 2008). However, this is the first study to present age- and sex-specific WC cutoff points for identifying abdominal obesity in European adolescents, by linking the current IDF criteria that is used for older adolescents and adults to adolescence periods using the $L M S$ method. 
TA B LE 2 Age-specific waist circumference cut-off point and corresponding percentiles for boys and girls

\begin{tabular}{|c|c|c|c|c|c|c|c|c|c|c|}
\hline \multirow[b]{3}{*}{ Age (years) } & \multicolumn{5}{|c|}{ Boys WC $(\mathrm{cm})$} & \multicolumn{5}{|c|}{ Girls WC $(\mathrm{cm})$} \\
\hline & \multicolumn{2}{|c|}{ IDF youth } & \multicolumn{2}{|c|}{ Age-specific } & \multirow[b]{2}{*}{$P^{\mathrm{a}}$} & \multicolumn{2}{|c|}{ IDF youth } & \multicolumn{2}{|c|}{ Age-specific } & \multirow[b]{2}{*}{$P^{\mathrm{a}}$} \\
\hline & $\left(90^{\text {th }}\right)$ & $\mathbf{N}^{+}$ & $\left(97^{\text {th }}\right)$ & $\mathbf{N}^{+}$ & & $\left(90^{\text {th }}\right)$ & $\mathbf{N}^{+}$ & $\left(87^{\text {th }}\right)$ & $\mathbf{N}^{+}$ & \\
\hline 10 & 76.5 & 63 & 84.3 & 20 & $*$ & 73.0 & 90 & 71.5 & 59 & $*$ \\
\hline 11 & 77.5 & 142 & 85.2 & 38 & $*$ & 75.1 & 148 & 73.6 & 159 & $*$ \\
\hline 12 & 79.3 & 173 & 86.9 & 63 & * & 77.4 & 142 & 75.8 & 170 & $*$ \\
\hline 13 & 81.1 & 174 & 88.5 & 77 & $*$ & 78.9 & 151 & 77.3 & 182 & $*$ \\
\hline 14 & 82.5 & 137 & 89.8 & 45 & $*$ & 79.6 & 133 & 78.0 & 152 & $*$ \\
\hline 15 & 83.9 & 150 & 91.2 & 63 & $*$ & 80.4 & 170 & 78.8 & 179 & $*$ \\
\hline 16 & 85.2 & 126 & 94.0 & 61 & - & 81.5 & 153 & 80.0 & 235 & - \\
\hline Total & - & 1654 & - & 368 & $*$ & - & 987 & - & 1138 & $*$ \\
\hline
\end{tabular}

IDF youth: International Diabetes Federation pediatric criteria; Age-specific: Growth curve using the LMS method; $\mathrm{N}^{+}$: Number of subjects identified with abdominal obesity.

${ }^{a}$ Compares the prevalence of abdominal obesity of the pediatric IDF criteria with the LMS growth curves method. $*(P<.05) \chi^{2}$ test.

The present study provided WC age- and sex-specific cutoff points for boys and girls aged 10 to 15 years that are in accordance with current IDF recommended cutoff points for those aged 16 years and older. A similar approach has been used by Jolliffe and Janssen (2007), with North American adolescents (12 to 19 years old). They identified the $83^{\text {rd }}$ percentile for boys and the $50^{\text {th }}$ percentile for girls as intercepting the WC cut-off point for adults established by the IDF. Benmohammed et al. (2016) conducted a similar approach in Algerian adolescents, observing that the $95^{\text {th }}$ percentile for boys and the $67^{\text {th }}$ percentile for girls crossed the IDF cutoffs of $94 \mathrm{~cm}$ for men and $80 \mathrm{~cm}$ for women, respectively. In the present study, it was shown that the percentile for identifying girls with abdominal obesity was lower than that observed for boys, with the $97^{\text {th }}$ and $87^{\text {th }}$ percentile for boys and girls, respectively, corresponding to the adult criteria. This study shows that the use of the $90^{\text {th }}$ percentile, currently recommended by the IDF for 10-15 yearolds, might not compensate for each population-specific characteristics because it either underestimates or overestimates the number of adolescents at risk.

Furthermore, for both boys and girls, the percentiles created for North American (Jolliffe \& Janssen, 2007) youth and for Algerian girls (Benmohammed et al., 2016) were different than those observed in the current investigation. This indicates that there is a need for demographic and ethnicspecific growth curves to be produced, as previously suggested by the IDF (Zimmet et al., 2007). Worldwide, the prevalence of abdominal obesity varies from $3.8 \%$ to $51.7 \%$ among adolescents from developing countries and from $8.7 \%$ to $33.2 \%$ among those from developed countries (de Moraes et al., 2011). Consequently, it is essential that a method that
Boys

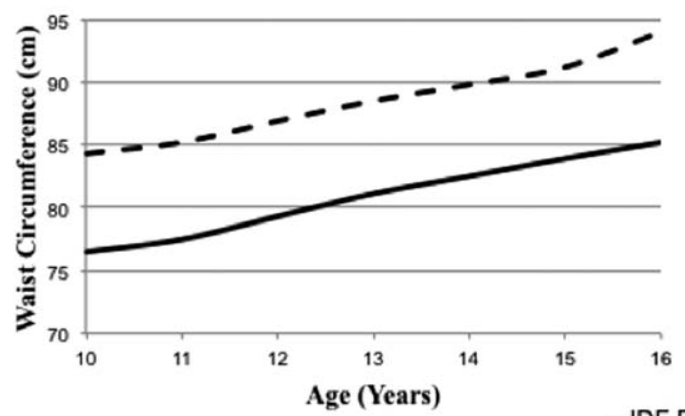

Girls

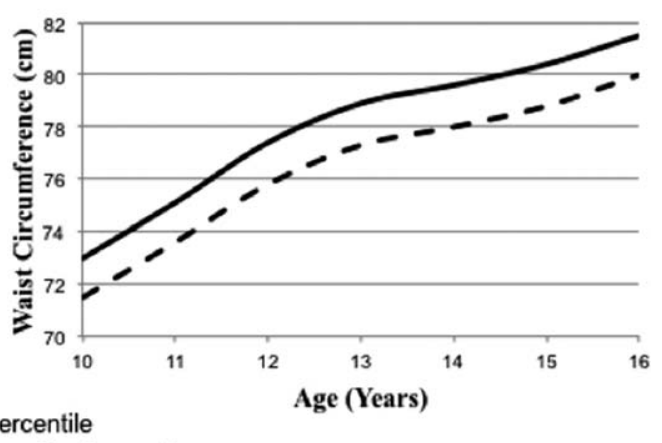

F IG URE 1 Waist circumference growth curves for boys and girls in accordance with two methods: 90th percentile (recommended by the International Diabetes Federation for adolescents) and age-specific growth curves linked to adult's cut-off 
not only reduces ethnic differences but is also accepted globally can be adopted, similar to the IDF cut-off points for adults (Alberti et al., 2006).

In the IDF experts' consensus statement (Zimmet et al., 2007), the $90^{\text {th }}$ percentile was suggested as the cut-off point for adolescents aged 10 to 15 years, adopting adult criteria at the age of 16 and above. The establishment of the $90^{\text {th }}$ percentile in the IDF experts' consensus statement was based on a study performed on 818 pre-pubertal children aged 3 to 11 years old (Maffeis, Pietrobelli, Grezzani, Provera, \& Tato, 2001) indicating that those with a WC above the $90^{\text {th }}$ percentile had a higher probability of developing multiple risk factors, particularly an adverse lipid profile and hypertension (Maffeis et al., 2001). Evidence supporting the previous IDF recommendations arises from an investigation with children younger than 11 years, but hormonal, metabolic and psychological changes caused by puberty have been recognized (Tfayli \& Arslanian, 2007). It was thus considered in this study that a cross-sectional percentile throughout adolescence might not compensate for metabolic instability.

Taking into account previous findings (Benmohammed et al., 2016; Jolliffe \& Janssen, 2007) and based on information from the present study, it is believed that the LMS growth curves method for developing age- and sex-specific cut-off points linked to current IDF adult criteria might better compensate for sex differences throughout adolescence, as they are a more suitable diagnostic tool in both research and clinical practice. Furthermore, it should be noted that the WC is an inexpensive, highly sensitive and reproducible tool, which is useful for measuring abdominal obesity and enables large sample sizes.

However, the results of this study are subject to the following limitations. The lack of the inclusion of a measure of sexual maturation in the analysis may be regarded as a drawback. In fact, the growth curves are related to changes in chronological age rather than maturational level, but this approach would not be suitable for clinical use as maturational level would have to be assessed.

Another important issue is the lack of other MetS variables. It would be of interest to extend the analysis to the remaining variables so that a complete diagnostic set could be obtained. Nevertheless, it is important to emphasize that the IDF states that abdominal obesity is the sine qua non condition for the MetS diagnosis both in adult (Alberti et al., 2006) and pediatric ages (Zimmet et al., 2007). Additionally, although it is a common practice to use cross-sectional data for developing growth curves, it would be preferable to use the method with longitudinal data.

This study presents the first age- and sex-specific WC cut-off points, linked to internationally recommended cut-off points for older adolescents and adults (16+ years old), for diagnosing abdominal obesity in adolescents aged 10 to 15 years. The current IDF pediatric cutoff points for WC might not compensate for adolescents' metabolic instability. More important than the discussion about the method for diagnosing abdominal obesity in youth, it is expected that healthcare professionals could benefit from the results of this study when used in a clinical setting. Using these cutoffs will allow clinicians to identify those at risk for adulthood abdominal obesity. Particularly when using multiple time-points, those boys and girls falling in the $97^{\text {th }}$ and $87^{\text {th }}$ percentiles should be targeted for lifestyles interventions.

\section{ACKNOWLEDGMENTS}

The authors are grateful to the participating children and to all technical staff involved in data collection procedures. Grant sponsor: DAS is supported by a scholarship from the Portuguese Foundation for Science and Technology; grant number: SFRH/BPD/92462/2013.

\section{AUTHORS' CONTRIBUTIONS}

Designed the study: Luís B. Sardinha.

Responsible for data collection: Jorge Bravo, Armando M. Raimundo, and Diana A. Santos.

Analyzed the data and drafted the manuscript, which was reviewed by Rafael Timón and Luís B. Sardinha: Jorge Bravo, Armando M. Raimundo, and Diana A. Santos.

\section{CONFLICT OF INTEREST STATEMENT}

No conflict of interest was declared.

\section{REFERENCES}

Alberti, K. G., Zimmet, P., \& Shaw, J. (2006). Metabolic syndrome-a new world-wide definition. A Consensus Statement from the International Diabetes Federation. Diabetic Medicine, 23(5), 469-480.

Benmohammed, K., Valensi, P., Balkau, B., \& Lezzar, A. (2016). Metabolic syndrome in adolescents: definition based on regression of IDF adult cut-off points. Public Health, 141, 88-94.

Brambilla, P., Bedogni, G., Moreno, L. A., Goran, M. I., Gutin, B., Fox, K. R., .. Pietrobelli, A. (2006). Crossvalidation of anthropometry against magnetic resonance imaging for the assessment of visceral and subcutaneous adipose tissue in children. International Journal of Obesity (London), 30(1), 23-30.

CDC. (2007). National Health and Nutrition Examination Survey (NHANES): Anthropometry Procedures Manual.

Cole, T. J., Bellizzi, M. C., Flegal, K. M., \& Dietz, W. H. (2000). Establishing a standard definition for child overweight and obesity worldwide: international survey. BMJ, 320(7244), 1240-1243.

Cole, T. J., \& Green, P. J. (1992). Smoothing reference centile curves: the LMS method and penalized likelihood. Statistics in Medicine, 11(10), 1305-1319.

Eisenmann, J. C. (2005). Waist circumference percentiles for 7- to 15-year-old Australian children. Acta Paediatrica, 94(9), 11821185. 
Eisenmann, J. C., Welk, G. J., Wickel, E. E., \& Blair, S. N., Aerobics Center Longitudinal S. (2004). Stability of variables associated with the metabolic syndrome from adolescence to adulthood: The Aerobics Center Longitudinal Study. American Journal of Human Biology, 16(6), 690-696.

Fernandez, J. R., Redden, D. T., Pietrobelli, A., \& Allison, D. B. (2004). Waist circumference percentiles in nationally representative samples of African-American, European-American, and Mexican-American children and adolescents. Journal of Pediatrics, 145(4), 439-444.

Fredriks, A. M., van Buuren, S., Fekkes, M., Verloove-Vanhorick, S. P., \& Wit, J. M. (2005). Are age references for waist circumference, hip circumference and waist-hip ratio in Dutch children useful in clinical practice? The European Journal of Pediatrics, 164 (4), 216-222.

Freedman, D. S., Kahn, H. S., Mei, Z., Grummer-Strawn, L. M., Dietz, W. H., Srinivasan, S. R., \& Berenson, G. S. (2007). Relation of body mass index and waist-to-height ratio to cardiovascular disease risk factors in children and adolescents: the Bogalusa Heart Study. The American Journal of Clinical Nutrition, 86(1), $33-40$.

Hatipoglu, N., Ozturk, A., Mazicioglu, M. M., Kurtoglu, S., Seyhan, S., \& Lokoglu, F. (2008). Waist circumference percentiles for 7to 17 -year-old Turkish children and adolescents. European Journal of Pediatrics, 167(4), 383-389.

Hirschler, V., Aranda, C., Calcagno, M., Maccalini, G., \& Jadzinsky, M. (2005). Can waist circumference identify children with the metabolic syndrome? Archives of Pediatrics and Adolescent Medicine, 159(8), 740-744.

Inokuchi, M., Matsuo, N., Anzo, M., Takayama, J. I., \& Hasegawa, T. (2007). Age-dependent percentile for waist circumference for Japanese children based on the 1992-1994 cross-sectional national survey data. European Journal of Pediatrics, 166(7), 655-661.

Jolliffe, C. J., \& Janssen, I. (2007). Development of age-specific adolescent metabolic syndrome criteria that are linked to the Adult Treatment Panel III and International Diabetes Federation criteria. Journal of the American College of Cardiology, 49(8), 891-898.

Kahn, H. S., Imperatore, G., \& Cheng, Y. J. (2005). A populationbased comparison of BMI percentiles and waist-to-height ratio for identifying cardiovascular risk in youth. Journal of Pediatrics, 146(4), 482-488.

Katzmarzyk, P. T., Perusse, L., Malina, R. M., Bergeron, J., Despres, J. P., \& Bouchard, C. (2001). Stability of indicators of the metabolic syndrome from childhood and adolescence to young adulthood: the Quebec Family Study. Journal of Clinical Epidemiology, 54(2), 190-195.

Lee, S., Bacha, F., \& Arslanian, S. A. (2006a). Waist circumference, blood pressure, and lipid components of the metabolic syndrome. Journal of Pediatrics, 149(6), 809-816.

Lee, S., Bacha, F., Gungor, N., \& Arslanian, S. A. (2006b). Waist circumference is an independent predictor of insulin resistance in black and white youths. Journal of Pediatrics, 148(2), 188-194.

Maffeis, C., Pietrobelli, A., Grezzani, A., Provera, S., \& Tato, L. (2001). Waist circumference and cardiovascular risk factors in prepubertal children. Obesity Research, 9(3), 179-187.
McCarthy, H., Jarrett, K., \& Crawley, H. (2001). Original Communications-The development of waist circumference percentiles in British children aged 5.0-16.9 y. Europen Journal of Clinical Nutrition, 55(10), 902-907.

Mesa, J. L., Ortega, F. B., Ruiz, J. R., Castillo, M. J., Tresaco, B., Carreno, F., ... Bueno, M. (2006). Anthropometric determinants of a clustering of lipid-related metabolic risk factors in overweight and non-overweight adolescents-influence of cardiorespiratory fitness. The Avena Study. Annals of Nutrition and Metabolism, 50 (6), 519-527.

de Moraes, A. C., Fadoni, R. P., Ricardi, L. M., Souza, T. C., Rosaneli, C. F., Nakashima, A. T., \& Falcao, M. C. (2011). Prevalence of abdominal obesity in adolescents: a systematic review. Obesity Reviews, 12(2), 69-77.

Moreno, L. A., Fleta, J., Mur, L., Rodriquez, G., Sarria, A., \& Bueno, M. (1999). Waist circumference values in Spanish children-gender related differences. European Journal of Clinical Nutrition, 53(6), 429-433.

Moreno, L. A., Pineda, I., Rodriguez, G., Fleta, J., Sarria, A., \& Bueno, M. (2002). Waist circumference for the screening of the metabolic syndrome in children. Acta Paediatrica, 91(12), 1307-1312.

Ng, M., Fleming, T., Robinson, M., Thomson, B., Graetz, N., Margono, C., ... Gakidou, E. (2014). Global, regional, and national prevalence of overweight and obesity in children and adults during 1980-2013: a systematic analysis for the Global Burden of Disease Study 2013. Lancet, 384(9945), 766-781.

de Onis, M., Blossner, M., \& Borghi, E. (2010). Global prevalence and trends of overweight and obesity among preschool children. The American Journal of Clinical Nutrition, 92(5), 1257-1264.

de Onis, M., Onyango, A. W., Borghi, E., Siyam, A., Nishida, C., \& Siekmann, J. (2007). Development of a WHO growth reference for school-aged children and adolescents. Bulletin of the World Health Organization, 85(9), 660-667.

Patry-Parisien, J., Shields, M., \& Bryan, S. (2012). Comparison of waist circumference using the World Health Organization and National Institutes of Health protocols. Health Reports, 23(3), 53-60.

Rosini, N., Machado, M. J., Webster, I. Z., Moura, S. A., Cavalcante Lda, S., \& da Silva, E. L. (2013). Simultaneous prediction of hyperglycemia and dyslipidemia in school children in Santa Catarina State, Brazil based on waist circumference measurement. Clinical Biochemistry, 46(18), 1837-1841.

Sardinha, L. B., Santos, R., Vale, S., Coelho e Silva, M. J., Raimundo, A. M., Moreira, H., ... Mota, J. (2012). Waist circumference percentiles for Portuguese children and adolescents aged 10 to 18 years. The European Journal of Pediatrics, 171(3), 499-505.

Sardinha, L. B., Santos, R., Vale, S., Silva, A. M., Ferreira, J. P., Raimundo, A. M., ... Mota, J. (2011). Prevalence of overweight and obesity among Portuguese youth: A study in a representative sample of 10-18-year-old children and adolescents. International Journal of Pediatric Obesity, 6(2Part2), e124-e128.

Savva, S. C., Tornaritis, M., Savva, M. E., Kourides, Y., Panagi, A., Silikiotou, N., ... Kafatos, A. (2000). Waist circumference and waist-to-height ratio are better predictors of cardiovascular disease 
risk factors in children than body mass index. International Journal of Obesity and Related Metabolic Disorders, 24(11), 1453-1458.

Schwandt, P., Kelishadi, R., \& Haas, G. M. (2008). First reference curves of waist circumference for German children in comparison to international values: the PEP Family Heart Study. World Journal of Pediatrics, 4(4), 259-266.

Singh, A. S., Mulder, C., Twisk, J. W. R., Van Mechelen, W., \& Chinapaw, M. J. M. (2008). Tracking of childhood overweight into adulthood: a systematic review of the literature. Obesity Reviews, 9(5), 474-488.

Tfayli, H., \& Arslanian, S. (2007). The challenge of adolescence: Hormonal changes and sensitivity to insulin. Diabetes Voice, 52, 28-30.

World Medical Association. (2013). World Medical Association Declaration of Helsinki: ethical principles for medical research involving human subjects. JAMA, 310(20), 2191-2194.
Yan, W., Yao, H., Dai, J., Cui, J., Chen, Y., Yang, X., ... Wang, X. (2008). Waist circumference cutoff points in school-aged Chinese Han and Uygur children. Obesity (Silver Spring), 16(7), 16871692.

Zimmet, P., Alberti, K. G., Kaufman, F., Tajima, N., Silink, M., Arslanian, S., ... Caprio, S. (2007). The metabolic syndrome in children and adolescents - an IDF consensus report. Pediatric Diabetes, 8(5), 299-306.

How to cite this article: Bravo J, Raimundo AM, Santos DA, Timón R, Sardinha LB. Abdominal obesity in adolescents: Development of age-specific waist circumference cut-offs linked to adult IDF criteria. Am J Hum Biol. 2017;e23036. https://doi.org/10.1002/ajhb.23036 